Available online at www.sciencedirect.com

ELSEVIER

\title{
Taxonomic status and intraspecific phylogeography of two sibling species of Metaphire (Oligochaeta: Megascolecidae) in Taiwan
}

\author{
Chih-Han Chang ${ }^{\mathrm{a}}$, Jiun-Hong Chen ${ }^{\mathrm{a}, \mathrm{b}, *}$
}

\author{
anstitute of Zoology, National Taiwan University, No. 1, Roosevelt Road, Section 4, Taipei 106, Taiwan \\ ${ }^{\mathrm{b}}$ Department of Life Science, National Taiwan University, No. 1, Roosevelt Road, Section 4, Taipei 106, Taiwan
}

Received 20 November 2004; accepted 4 July 2005

KEYWORDS

Taxonomy;

Earthworms;

Phylogeography;

Cytochrome $c$

oxidase subunit I;

Amynthas;

Metaphire

\begin{abstract}
Summary
In this study the synonymy of Amynthas formosae (Michaelsen, 1922) and A. yuhsii (Tsai, 1964) are reevaluated and the intraspecific phylogeography between them is studied. The morphological comparison and phylogenetic analysis based on cytochrome $c$ oxidase subunit I suggest that $A$. formosae and $A$. yuhsii are not synonyms and both of them belong to Metaphire. The phylogeographic analysis suggests that the formation of mountains and rivers during the uplift of the Western Foothills in Taiwan comprised the vicariance events responsible for the intraspecific genetic differentiation between these two species.

(c) 2005 Elsevier GmbH. All rights reserved.
\end{abstract}

\section{Introduction}

Pheretimoid earthworms are a large group within the Megascolecidae. They were previously included in the genus Pheretima and were divided into 10 genera by Sims and Easton (Sims and Easton, 1972; Easton, 1979, 1982). Amynthas and Metaphire are two common genera of pheretimoid earthworms in East Asia. Most of the characters of the two genera are

\footnotetext{
*Corresponding author. Department of Life Science, National Taiwan University, No. 1, Roosevelt Road, Section 4, Taipei 106, Taiwan. Tel.: +886223630231 x 2354; fax: +886223658912.

E-mail address: chenjh@ntu.edu.tw (J.-H. Chen).
}

similar. The diagnostic character between them is that Metaphire has copulatory pouches in the male pore areas but Amynthas does not (Sims and Easton, 1972). Amynthas formosae (Michaelsen, 1922) is a common earthworm species in western Taiwan. It was first described as Pheretima formosae, and was later included in the genus Amynthas of pheretimoid earthworms by Sims and Easton (1972). A. yuhsi (Tsai, 1964 ) is regarded as a synonym of $A$. formosae (Tsai et al., 2000a). The former name should be corrected to $A$. yuhsii because it was the stated patronym for Dr. Yu-Hsi Wang (R. J. Blakemore, pers. commun.). However, in earthworm surveys during the past 2 years we found that different populations of 
A. formosae exhibit different distances between the paired spermathecal pores. This morphological difference may be correlated with genetic differentiation. If genetic differentiation has occurred, the different populations may correspond to different subspecies or even different species. Therefore, we doubt whether $A$. yuhsii is a synonym of $A$. formosae.

Recently, molecular data have been widely used in taxonomic and phylogenetic studies in many animals, including the Oligochaeta. Reported studies have included leeches (Siddall and Burreson, 1998; Apakupakul et al., 1999; Siddall and Borda, 2003; Borda and Siddall, 2004), aquatic oligochaetes (Nylander et al., 1999; Erseus et al., 2000, 2002; Beauchamp et al., 2001; Bely and Wray, 2004), and terrestrial earthworms (Jamieson et al., 2002; Pop et al., 2003; Heethoff et al., 2004). Some molecular markers such as the DNA sequence of cytochrome $c$ oxidase and 16S rRNA have been demonstrated to be useful in studying the taxonomy and phylogeny of earthworms.

Therefore, in this study, we compared the morphological differences and applied a molecular technique to unravel the synonymy of $A$. yuhsii and $A$. formosae. To avoid confusion, we will represent A. formosae sensu Tsai et al. (2000a) as 'Amynthas (A.) formosae' throughout this paper.

\section{Materials and methods}

\section{Sample collection and preservation}

During 2002-2004 we conducted an extensive field survey of earthworms throughout Taiwan. Samples of 'A. formosae' were collected from various localities. Adult, clitellate earthworms were anesthetized in a $10 \%$ ethanol solution. Muscle tissues, $0.2-2 \mathrm{~g}$, were isolated and preserved in a $120 \mathrm{ml} 70 \%$ or $95 \%$ ethanol solution for DNA extraction. The residual earthworm samples were fixed in $10 \%$ formalin and preserved in a $70 \%$ ethanol solution. Four species closely related to 'A. formosae', including Metaphire paiwanna, M. bununa, M. yuanpowa, and M. tahanmonta (Chang and Chen, 2005), and two other Metaphire, M. schmardae schmardae and M. californica, collected in Taiwan were treated using the same procedures for the phylogenetic analysis.

\section{Morphological comparison}

The characters described in the original description of $A$. formosae and $A$. yuhsii were used to compare the 52 specimens collected from different localities. Published papers concerning the taxon- omy of $A$. formosae and $A$. yuhsii were also reviewed. We also reexamined the specimens reported in Chen and Shih (1996), Chuang et al. (2002) and Chen et al. (2003).

\section{DNA extraction, PCR and DNA sequencing}

Muscle tissues were washed with distilled water, homogenized in liquid nitrogen and digested in digestion buffer $(10 \mathrm{mM}$ Tris- $\mathrm{HCl}, 2 \mathrm{mM}$ dihydrate EDTA, $10 \mathrm{mM} \mathrm{NaCl}, 10 \mathrm{mg} \mathrm{ml}^{-1}$ DTT, $1 \%$ SDS, and $0.4 \mathrm{mg} \mathrm{ml}^{-1}$ protease $\mathrm{K}$ ) at $50^{\circ} \mathrm{C}$ for $15-30 \mathrm{~min}$. Total DNA was extracted from the digested tissue-buffer solution with a standard phenol/chloroform extraction method followed by ethanol precipitation (Palumbi et al., 1991). The ethanol-precipitated DNA was dissolved in distilled water, checked with $1.0 \%$ agarose gel electrophoresis and stored at $-20^{\circ} \mathrm{C}$.

A 535-bp mitochondrial cytochrome $c$ oxidase subunit I (COI) DNA fragment was amplified using the universal primers LC01490: 5'-GGT CAA CAA ATC ATA AAG ATA TTG G-3' and HCO2198: 5'-TAA ACT TCA GGG TGA CCA AAA AAT CA-3' (Folmer et al., 1994). PCR amplifications were carried out in a $50 \mu$ total volume using 1 cycle at $94^{\circ} \mathrm{C}$ for $1 \mathrm{~min}$, followed by 35 cycles of denaturation for $30 \mathrm{~s}$ at $94^{\circ} \mathrm{C}$, annealing for $30 \mathrm{~s}$ at $54^{\circ} \mathrm{C}$, and extension for $50 \mathrm{~s}$ at $72^{\circ} \mathrm{C}$, with a final cycle at $72{ }^{\circ} \mathrm{C}$ for $10 \mathrm{~min}$.

PCR products were checked using $1.0 \%$ agarose gel electrophoresis and sequenced in both directions using the same primers in PCR. Sequencing was performed with the Dyenamic ET dye terminator cycle sequencing kit (Amersham Biosciences). Products were analyzed with a MegaBACE 500 automated sequencer (Amersham Biosciences). The computer base calling was double-checked by eye.

\section{Sequence alignment and phylogenetic analysis}

The sequence was checked by aligning the sequencing results with the $\mathrm{COI}$ full sequence of Lumbricus terrestris (GenBank accession no. U24570) using the default settings of Clustal W 1.82 (Thompson et al., 1994).

Sequences of $L$. terrestris and Pontodrilus litoralis were retrieved from GenBank and used in the phylogenetic analysis. The former was used to root the phylogenetic trees. Alignments among all sequences analyzed were performed using the default settings of Clustal W 1.82. A homologous fragment of $535 \mathrm{bp}$ of the $\mathrm{CO}$ sequence was used in this study. The sequence obtained was submitted to GenBank (Table 1). Neighbor joining (NJ) analyses were performed using Mega 2.1 (Kumar et al., 2001) with 
Table 1. Samples used in the phylogenetic study and the corresponding GenBank accession numbers

\begin{tabular}{|c|c|c|c|}
\hline Species & Locality & Sample no. & Accession no. \\
\hline \multirow{17}{*}{$\begin{array}{l}\text { 'Amynthas formosae' (northern } \\
\text { group = Metaphire yuhsii) }\end{array}$} & Hsintien, Taipei County & B0665 & AY739309 \\
\hline & Wulia, Taipei County & B0650 & AY739310 \\
\hline & Shouyi, Taipei County & B0604 & AY739311 \\
\hline & Wanli, Taipei County & B0601 & AY739312 \\
\hline & Tamsui, Taipei County & B0612 & AY739313 \\
\hline & Sanchih, Taipei County & B0611 & AY739314 \\
\hline & Tuchen, Taipei County & B0663 & AY739315 \\
\hline & Sanshia, Taipei County & B0607 & AY739316 \\
\hline & Mucha, Taipei City & B0602 & AY739317 \\
\hline & Nangang, Taipei City & B0625 & AY739318 \\
\hline & Keelung City & B0624 & AY739319 \\
\hline & Taoyuan, Taoyuan County & B0660 & AY739320 \\
\hline & Lungtan, Taoyuan County & B0619 & AY739321 \\
\hline & Fushin, Taoyuan County & B0657 & AY739322 \\
\hline & Chudong, Hsinchu County & B0628 & AY739323 \\
\hline & Guanhsi, Hsinchu County & B0659 & AY739324 \\
\hline & Jianshi, Hsinchu County & B0637 & AY739325 \\
\hline \multirow{9}{*}{$\begin{array}{l}\text { 'A. formosae' (southern group = } \\
\text { M. formosae) }\end{array}$} & Yamgmei, Taoyuan County & B1801 & AY739326 \\
\hline & Baushan, Hsinchu County & B1808 & AY739327 \\
\hline & Sanwan, Miaoli County & B1811 & AY739328 \\
\hline & Sanyi, Miaoli County & B1847 & AY739329 \\
\hline & Nanchuang, Miaoli County & B1855 & AY739330 \\
\hline & Heping, Taichung County & B1875 & AY739331 \\
\hline & Guoshing, Nantou County & B1867 & AY739332 \\
\hline & Shinyi, Nantou County & B18105 & AY739333 \\
\hline & Mayshan, Chiayi County & B1899 & AY739334 \\
\hline M. tahanmonta & Taoyuan, Kaohsiung County & & AY739335 \\
\hline M. paiwanna & Liouguei, Kaohsiung County & & AY739336 \\
\hline M. bununa & Heping, Taichung County & & AY739337 \\
\hline M. yuanpowa & Wulia, Taipei County & & AY739338 \\
\hline M. californica & Taipei City & & AY739339 \\
\hline M. schmardae schmardae & Taipei City & & AY739340 \\
\hline Lumbricus terrestris & & & U24570 \\
\hline Pontodrilus litoralis & & & AF003256 \\
\hline
\end{tabular}

Kimura's two-parameter model (Kimura, 1980). Maximum parsimony (MP) analyses were performed using PAUP 4.0b10 (Swofford, 2000) with heuristic searches, random starting trees, 100 random additions of sequences and TBR branch swapping. Gaps in the DNA sequences were treated as missing data and were eliminated from both of the analyses. Bootstrapping of 1000 pseudo-replicates for the NJ and MP analyses was used to examine the robustness of clades and their phylogenetic relationships.

\section{Results}

\section{Morphological comparison}

The morphological comparison resulted in two different groups of ' $A$. formosae' (Table 2). Although the characters, including body length, segment number, seta number, spermathecae, testis, seminal vesicle and male pores, showed no obvious differences, the distance between the paired spermathecal pores separated the earthworm samples into two groups (Fig. 1). The dorsal distances between the paired spermathecal pores were $0.093 \pm 0.0168$ (mean $\pm \mathrm{SD}, n=22$ ) body circumferences in the southern group and $0.038 \pm 0.0047$ (mean \pm SD, $n=30$ ) body circumferences in the northern group. Apparently, the dorsal distance between the paired spermathecal pores is wider in the southern group than in the northern group. In addition, these two groups have an allopatric distribution (Fig. 2).

\section{Sequence characteristics and phylogenetic analysis}

From 26 individuals of ' $A$. formosae', 26 haplotypes of the $\mathrm{COI}$ gene were observed. Within these 
Table 2. Comparison of the two groups of 'Amynthas formosae' (spermathecae in 6-9, testes in 10, and seminal vesicles in 11)

\begin{tabular}{lll}
\hline Character & Northern group $(n=30)$ & Southern group $(n=22)$ \\
\hline Locality & North of Hsinchu Co. & South of Hsinchu Co. \\
Length $(\mathrm{mm})$ & $177-318$ & $159-393$ \\
$\begin{array}{l}\text { Number of segments } \\
\text { Number of setae between male }\end{array}$ & $80-163$ & $103-176$ \\
$\quad 14-34$ & $19-32$ \\
$\quad$ pores & Present & Present \\
$\begin{array}{l}\text { Number of oval pads in male pore } \\
\quad 1 \text { area }\end{array}$ & 1 & 1 \\
$\begin{array}{l}\text { Distance between paired } \\
\quad \text { spermathecal pores through the } \\
\text { dorsal side }\end{array}$ & $2.9-4.8 \%$ of body circumference & $7.3-12.5 \%$ of body circumference \\
\end{tabular}

(a)

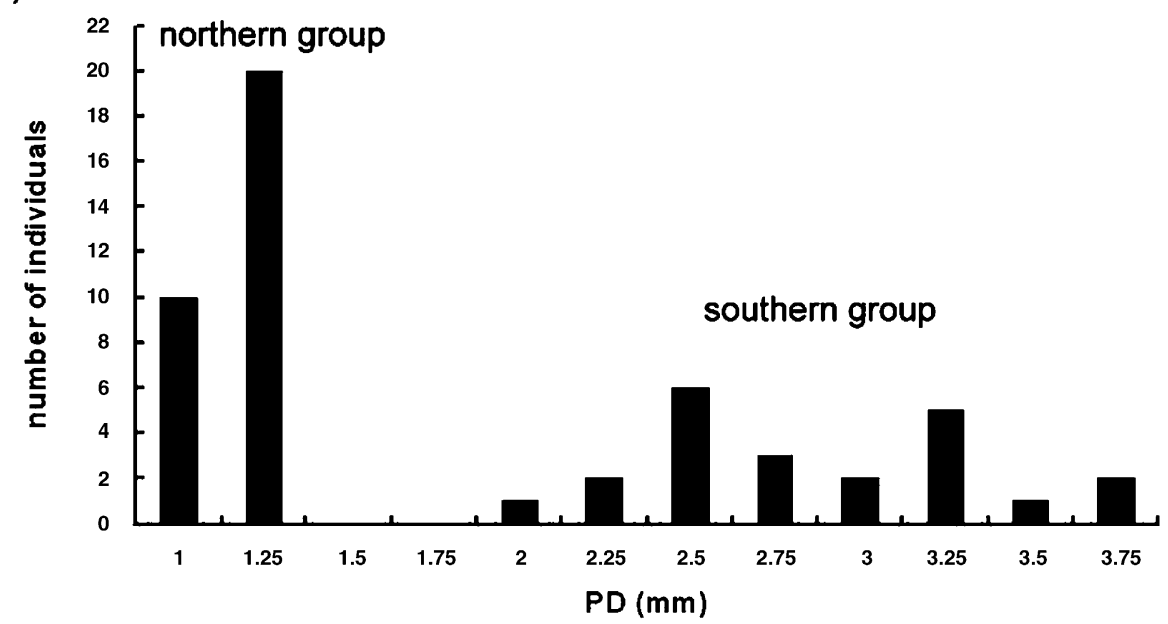

(b)

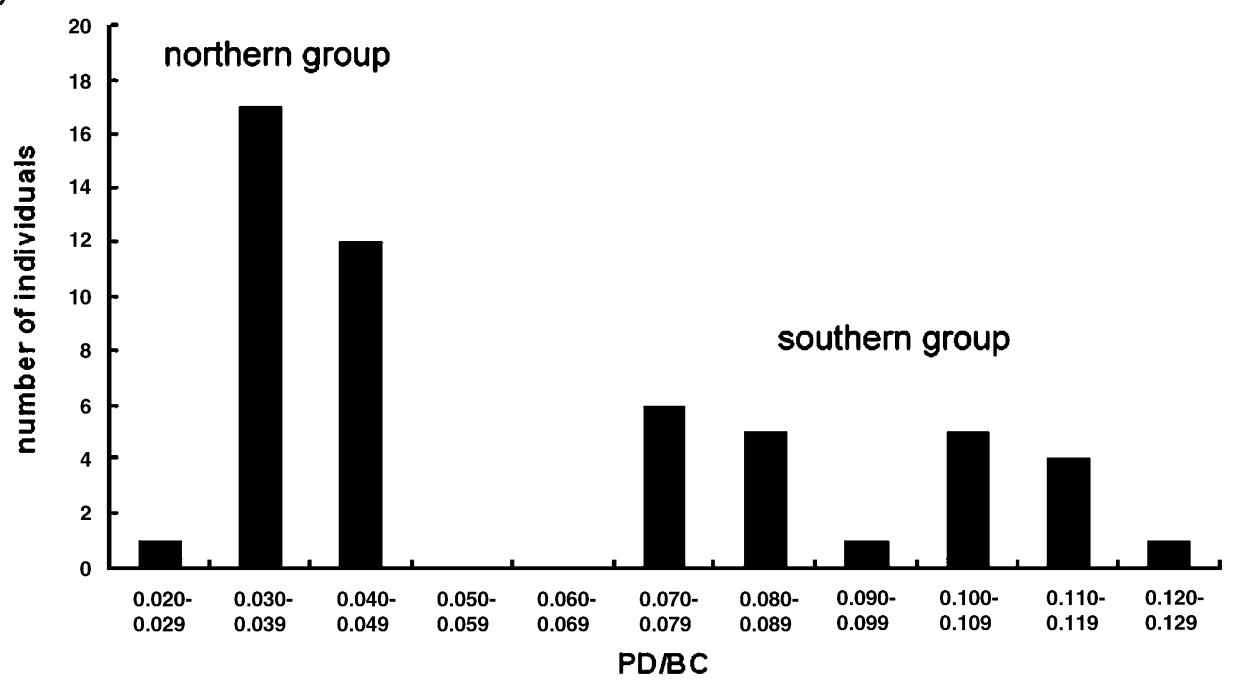

Figure 1. Distances between the paired spermathecal pores of 'Amynthas formosae'. PD, distance between the paired spermathecal pores dorsally; BC, body circumference. Two distinct groups (a northern group and a southern group) of 'A. formosae' are evident. (a) Number of individuals with different PDs. (b) Number of individuals with different ranges of $\mathrm{PD} / \mathrm{BC}$. 


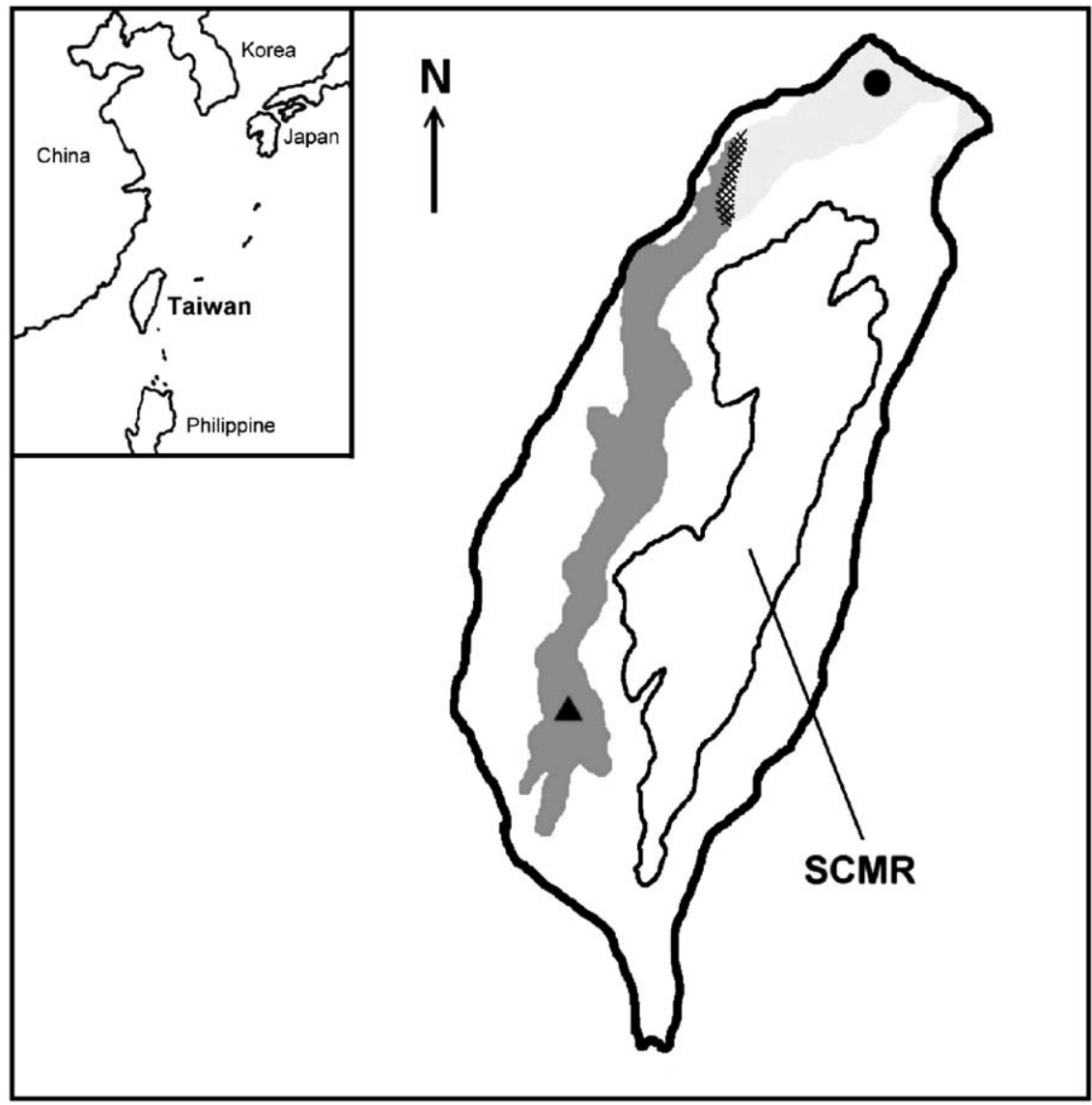

Figure 2. Location of Taiwan and the distribution of 'Amynthas formosae'. The Sheishan-Central Mountain Range (SCMR) runs generally north-south through the center of Taiwan. Marks show the type localities of Pheretima formosae Michaelsen, 1922 (triangle) and Pheretima yuhsi Tsai, 1964 (circle). The northern group in light gray and the southern group in dark gray, respectively in the morphological comparisons are marked. The area with crosshatching indicates regions where the two taxa are sympatrically distributed.

haplotypes 17 belonged to the northern group in the morphological comparison, nine to the southern group, and no shared haplotypes were found. In the 535-bp COI sequence, no insertions or deletions were found. Within ' $A$. formosae' 135 variable sites were observed, including 97 transitions, 10 transversions and 28 sites with both transitions and transversions. From the northern group 91 variable sites were observed, including 75 transitions, eight transversions and eight sites with both transitions and transversions. From the southern group 90 variable sites were observed, including 71 transitions, five transversions and 14 sites with both transitions and transversions.

The average genetic distance between the northern group and the southern group of 'A. formosae' was larger than that between any pair of M. paiwanna, M. yuanpowa, M. tahanmonta, and M. bununa (Table 3). Genetic distances between any individuals within each of the north- ern group and southern group were 0.002-0.101 and 0.029-0.103, respectively. Both of them were smaller than the genetic distance between the two groups.

For the 535-bp sequence, 186 variable sites were observed within Metaphire and ' $A$. formosae' in Taiwan, among which 144 sites were parsimonyinformative. The phylogenetic analysis resulted in a bootstrap consensus MP tree (Fig. 3a) of 757 steps, with a consistency index $(\mathrm{Cl})$ of 0.4108 , a homoplasy index $(\mathrm{HI})$ of 0.5892 , a retention index (RI) of 0.5897 and a rescaled consistency index (RC) of 0.2423 . The NJ tree has similar topologies to the MP tree and higher bootstrap values for some clades (Fig. 3b). The two trees strongly or moderately support both the monophyly of the northern group and southern group of ' $A$. formosae' with respect to the morphological comparison (clades A and B in Fig. 3; bootstrap values of 92 in the $\mathrm{NJ}$ tree and 77 in the MP tree for clade A, and 97 in the NJ tree 
Table 3. Pairwise comparisons of 'Amynthas formosae' and Metaphire species in Taiwan by Kimura's two-parameter distance

\begin{tabular}{llllllll}
\hline OTUs & AfoN & AfoS & Mpa & Mbu & Mta & Myu & Mca \\
\hline AfoS & 0.126 & & & & & & \\
Mpa & 0.123 & 0.116 & & & & & \\
Mbu & 0.120 & 0.135 & 0.111 & & & & \\
Mta & 0.120 & 0.130 & 0.111 & 0.117 & & & \\
Myu & 0.135 & 0.122 & 0.102 & 0.119 & 0.115 & 0.191 & 0.255 \\
Mca & 0.181 & 0.189 & 0.181 & 0.196 & 0.194 & 0.211 & 0.218 \\
Msc & 0.199 & 0.211 & 0.229 & 0.185 & 0.218 & \\
\hline
\end{tabular}

AfoN, northern group of 'A. formosae'; AfoS, southern group of 'A. formosae'; Mpa, M. paiwanna; Mbu, M. bununa; Mta, M. tahanmonta; Myu, M. yuanpowa; Mca, M. californica; Msc, M. schmardae schmardae.

(a)

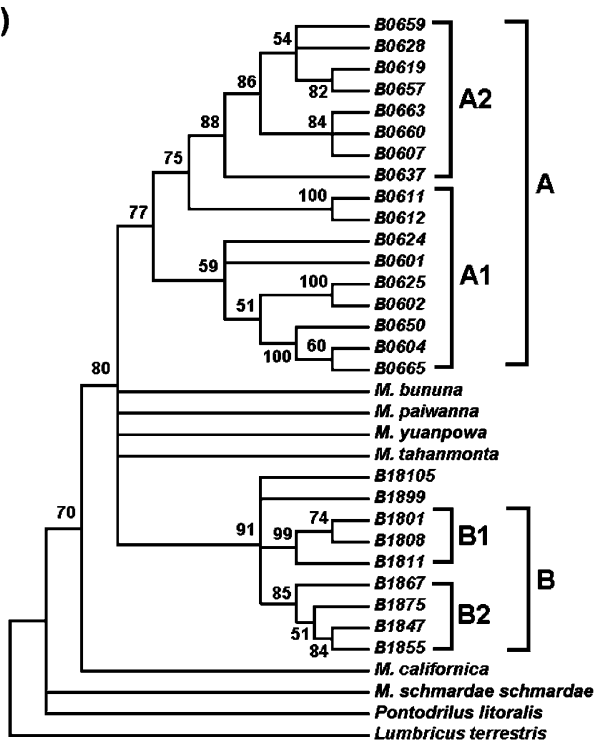

(b)

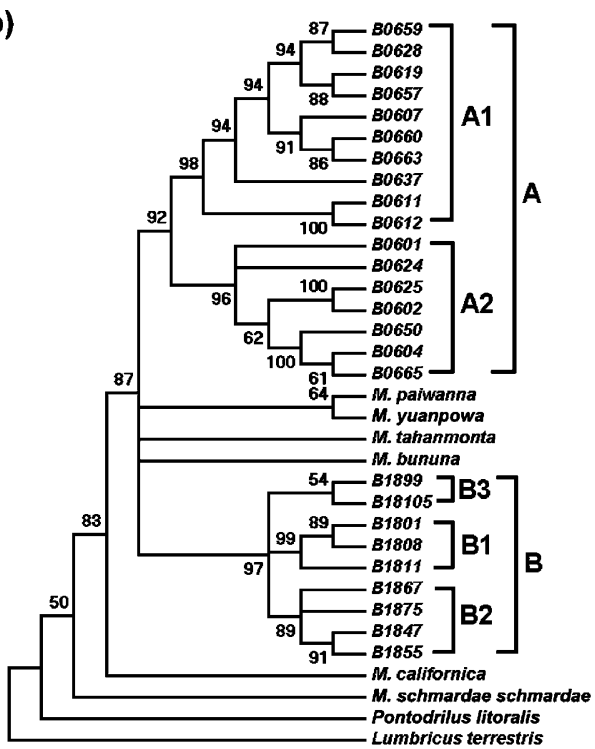

Figure 3. Phylogenetic trees of 'Amynthas formosae' reconstructed using the DNA sequence of the mitochondrial COI gene. (a) Cladogram of the maximum parsimony tree reconstructed using heuristic searches, 100 random additions of sequences, and TBR branch swapping. (b) Cladogram of the neighbor joining tree reconstructed using Kimura's twoparameter distance. In both trees, bootstrap values greater than 50 are indicated around the nodes and branches with those smaller than 50 being truncated. Clades within ' $A$. formosae' supported by bootstrap values greater than 50 are indicated in the figure.

and 91 in the MP tree for clade B), but not the monophyly of ' $A$. formosae'. Within clade A there were two distinct clades supported by bootstrap values higher than 50 in both the NJ and MP trees (bootstrap values of 98 in the NJ tree and 75 in the MP tree for clade A1, and 96 in the NJ tree and 59 in the MP tree for clade A2) (Fig. 3). The average genetic distance between these two clades was 0.088 , and the two clades have an allopatric distribution (Fig. 4b). Within clade B three clades were supported in the $\mathrm{NJ}$ tree with bootstrap values higher than 50 (clade B1, 99; clade B2, 89; clade B3, 54). But only two of them were supported in the MP tree (clade B1, 99; clade B2, 85) (Fig. 3). The average genetic distances between clades $B 1$ and B2, B1 and B3, and B2 and B3 were 0.088, 0.075 and 0.077 , respectively.

\section{Discussion}

\section{Historical review}

In 1922 P. formosae collected from Chiahsien, Kaohsiung County, southern Taiwan (Fig. 2) was described as a new species, with the illustration of one spermatheca and the associated diverticulum. $P$. formosae is a proandric earthworm with four pairs of spermathecae. The spermathecal pores are in 5/6-8/9. The paired spermathecal pores are close to the mediodorsal line and are separated by 0.125 body circumferences dorsally (Michaelsen, 1922). The holotype is preserved in the Rijksmuseum van Natuurlijke Histoire, The Netherlands (catalog no.: 1817). 
(a)

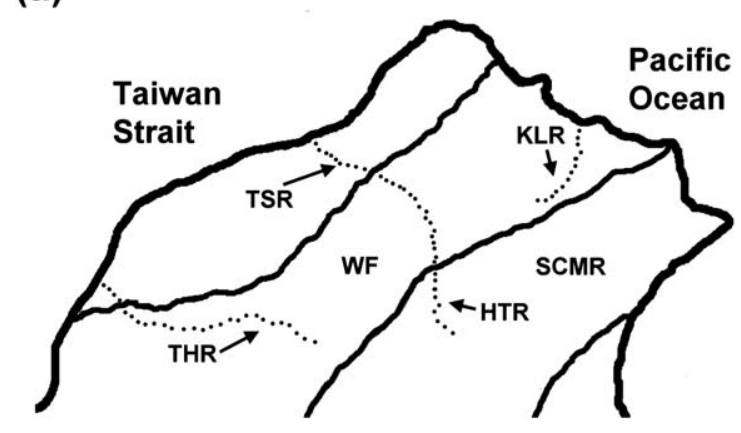

(b)

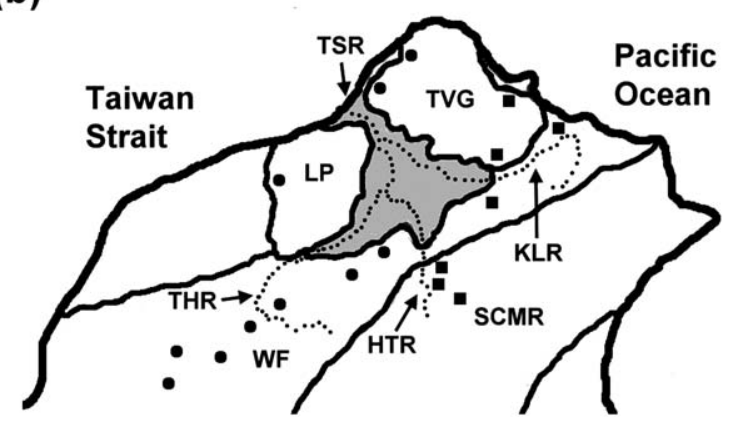

Figure 4. Map of the Taipei area and the collection sites of the northern group of 'Amynthas formosae' in the phylogenetic analysis. (a) The map of Taipei area about 2 million years ago. At that time, the Taipei area was part of the Western Foothills (WF). East of the Western Foothills was the higher Sheishan-Central Mountain Range (SCMR). The Hsintien River (HTR) was upstream of the Tamsui River (TSR), which ran directly into the sea near the present-day Taishan. The other two rivers (KLR, Keelung River and THR, Tahan River) in the Taipei area also directly emptied into the sea. (b) The map of the Taipei area at present and the collection sites of the northern group of ' $A$. formosae' in the phylogenetic analysis. The shaded area is the Taipei Basin, which is surrounded by the Linkou Plateau (LP), the Tatun Volcano Group (TVG), and the Western Foothills. The Tamsui River is composed of three rivers at present. Samples of clade A1 (closed circle) and A2 (closed square) of the northern group of ' $A$. formosae' in the phylogenetic analysis are allopatrically distributed, being separated by the Tatun Volcano Group and the Taipei Basin (TV/TB).

In 1964 Tsai described a new species, P. yuhsi, from Taipei in northern Taiwan (Fig. 2), with an illustration of the spermathecal pores, left male porophore, spermathecae, one prostate gland, sperm sacs, seminal vesicles and ovaries. In his description $P$. yuhsi is a proandric earthworm with four pairs of spermathecae. The spermathecal pores are in $6-9$, close to the anterior edge of each segment. The paired spermathecal pores are close to the medio-dorsal line, and the distance between them is equivalent to two or three setal intervals in the same segment. According to this description and the illustration in that paper, the distance between the paired spermathecal pores was about 0.01 body circumferences dorsally and they are immediately next to the medio-dorsal line. The type specimens are missing (Shih et al., 1999; C.-F. Tsai, pers. commun.).

In the revision of pheretimoid earthworms, Sims and Easton (1972) included $P$. formosae in the genus Amynthas. In 1996 A. formosae was collected in the Fushan Experimental Forest, northern Taiwan (Chen and Shih, 1996). Then, Shih et al. (1999) reviewed the earthworms from Taiwan. In that paper, A. formosae and A. yuhsi (former $P$. yuhsi $=A$. yuhsii) were kept apart as different species in the list. In 2000, A. formosae and A. yushi $(=A$. yuhsii) were both mentioned and kept apart as different species (Tsai et al., 2000b). However, Tsai et al. (2000a) compared the earthworm fauna between Taiwan and other areas in East Asia. It was the first time $P$. yushi $(=A$. yuhsii) was regarded as a synonym of $A$. formosae. A. formosae has also been reported by different field surveys in northern Taiwan (Chuang et al., 2002; Chen et al., 2003).

\section{Phylogenetic analysis}

The distance between the paired spermathecal pores of $A$. yuhsii described in the original paper is about 0.01 body circumferences apart dorsally (Tsai, 1964), while that of A. formosae described in the original paper was about 0.125 body circumferences apart dorsally (Michaelsen, 1922). Apparently, according to the original papers, the distance between the paired spermathecal pores of A. formosae is wider than that of $A$. yuhsii. In this study, similar results revealed that there are two groups, i.e. a northern group and a southern group, differing in the distance between the paired spermathecal pores within 'A. formosae'. The distances between the paired spermathecal pores are wider in the southern group than in the northern group. Furthermore, samples from Taipei, the type locality of $A$. yuhsii, belonged to the northern group of 'A. formosae', and those from Chiahsien in Kaohsiung County, the type locality of A. formosae, belonged to the southern group of 'A. formosae'. Consequently, the morphology of A. yuhsii described in the original paper matched the morphology of the northern group of 'A. formosae', and the morphology of $A$. formosae described in the original paper matched the morphology of the southern group of 'A. formosae'.

In addition, the results of the phylogenetic analysis do not support the monophyly of 
'A. formosae'. On the contrary, two monophyletic groups corresponding to the northern group and southern group in the morphological comparison are supported. The average genetic distance between the northern group and southern group of ' $A$. formosae' was larger than that between any pair of M. paiwanna, M. yuanpowa, M. tahanmonta, and $M$. bununa. Therefore, the two groups of 'A. formosae' presumably are indeed two distinct species. Based on this evidence from morphological comparison and phylogenetic analysis it is suggested that $A$. formosae and $A$. yuhsii are not synonyms. According to the results, 'A. formosae' reported in Chuang et al. (2002) and Chen et al. (2003) are indeed $A$. yuhsii, and those reported in Chen and Shih (1996) are misidentified M. taiwanensis.

In this study, the phylogenetic trees show that A. yuhsii, A. formosae, M. paiwanna, M. bununa, M. yuanpowa and M. tahanmonta form a monophyletic group. This result supports the view that A. formosae, M. paiwanna, M. bununa, M. yuanpowa and M. tahanmonta are closely related species (Chang and Chen, 2005). The genetic distances between each of the four gigantic Metaphire species (M. paiwanna, M. bununa, M. yuanpowa, and $M$. tahanmonta) and each of $A$. formosae and $A$. yuhsii are closer than those between each of the four gigantic Metaphire species and each of M. californica and M. schmardae schmardae. Also, the presence of copulatory pouches in the male pore areas of $A$. formosae and $A$. yuhsii imply that $A$. formosae and $A$. yuhsii should belong in Metaphire. In conclusion, the two species should be switched from Amynthas to Metaphire.

\section{Phylogeography}

Taiwan is an island about $170 \mathrm{~km}$ off the southeastern coast of China and is covered by mountains and hills. The Sheishan-Central Mountain Range runs north to south through the center of Taiwan. West to the Sheishan-Central Mountain Range is the Western Foothills region. Because of the collision between the Luzon Volcanic Arc and the Eurasian Continental Margin, the Western Foothills began to be uplifted above sea level about 3 MYA (Hsu and Sibuet, 1995; Teng et al., 2001). Before 2 MYA, the area around Taipei, a part of the Western Foothills, had been continuous hills. About 0.8 MYA, the hills in the Taipei area began to collapse and volcanic eruptions began at the northern tip of Taiwan. The collapse of the hills resulted in the formation of the Taipei Basin and the relative uplift of the Linkou Plateau west of the Taipei Basin and the volcanic eruptions resulted in the formation of the Tatun Volcano Group (Fig. 4) (Teng, 1996; Teng et al., 2001).

According to the phylogenetic analysis, there are two highly supported clades with different distributions within $M$. yuhsii. The two clades are now separated by the Tatun Volcano Group and Taipei Basin (TV/TB). Clade A1 lies west of the TV/TB, and clade A2 lies east of the TV/TB (Fig. 4b). The genetic differentiation between these two clades may have been the result of the formation of the TV/TB, which possibly served as geographical barriers between the eastern and western populations. The genetic distances between the two clades of $M$. yuhsii ranged between 0.071 and 0.101 , with a mean of 0.088 . Based on the above hypothesis, the evolutionary rate of the M. yuhsii $\mathrm{COI}$ gene has been about $0.11 \mathrm{MY}^{-1}$ between pairs of lineages $\left(0.11 \mathrm{MY}^{-1}\right.$ base pair $\left.{ }^{-1}\right)$, an evolutionary rate five times the common rate of animal mitochondrial genomes $\left(0.02 \mathrm{MY}^{-1}\right.$ base pair $^{-1}$, Avise, 2000).

The boundary between clades $A 1$ and $A 2$ in southern Taipei is Hsintien River, the upstream section of the ancient Tamsui River (Fig. 4a, b). Such a distribution evokes an alternative hypothesis: the genetic differentiation between the two clades of $M$. yuhsii began when the ancient Tamsui River formed about 2-3 MYA (Teng et al., 2001). The ancient Tamsui River may have divided $M$. yuhsii into a northern population (clade A2) and a southern population (clade A1). Northward dispersal events of the southern population occurred after the ancient Tamsui River changed its route northward about 0.8 MYA (Teng et al., 2001). According to this hypothesis and the acceptable formation time of the ancient Tamsui River, 2.5 MYA, the evolutionary rate of the $M$. yuhsii $\mathrm{COI}$ gene is estimated to be about $0.035 \mathrm{MY}^{-1}$ base pair ${ }^{-1}$. This evolutionary rate is similar to those in common animal mitochondrial genomes (Avise, 2000). This vicariance hypothesis better fits with the geological history and the ancient topography, and seems to be more reasonable.

In the phylogenetic analysis of $M$. formosae, clades B1 and B2 are supported by both the NJ and MP trees. However, perhaps because of the small sample size used in this study, clade B3 is weakly supported in the NJ tree but not in the MP tree, and the phylogenetic relationships among these three clades are unclear. But similar to the pattern of M. yuhsii, the three clades have an allopatric distribution, separated by large rivers in the Western Foothills. This distribution indicates that the three clades differentiated during the processes of the rise of the Western Foothills and the 
formation of the large rivers. This vicariance hypothesis is also supported by the estimated divergence times among different clades of $M$. formosae, which could be estimated using the evolutionary rate of the M. yuhsii COI gene as done in this study. The estimation resulted in divergence times of 2.1-2.5 MYA among the different clades of $M$. formosae. These estimated divergence times fall within the time range of the formation of the Western Foothills. Therefore, composed of vicariance events including the rise of the Western Foothills and the formation of large rivers, the processes of the genetic differentiation of different clades within $M$. yuhsii and $M$. formosae were very similar.

Another interesting phenomenon about the two species is their mating behavior. Generally, for most of the other earthworm species, two individuals lie together in parallel with the ventral parts of their bodies in contact when they are mating. This ventral-to-ventral mating behavior is facilitated by the ventrally or laterally positioned reproductive openings, including the spermathecal pores. However, the spermathecal pores of both M. yuhsii and $M$. formosae are dorsally positioned. Because the mating behaviors of these two species have not yet been observed in the field or in the laboratory, it is hard to imagine their mating behavior with the unusual position of the spermathecal pores. Overall, we have demonstrated that two different earthworm populations could have undergone significant genetic differentiation within northern Taiwan, and two neighboring populations with very similar morphology are indeed two distinct species, not geographical variations of a single species. Therefore, we believe that the taxonomic status of some widely distributed earthworm species with geographical morphological variations, such as $A$. robustus, should be reevaluated using both morphological and phylogenetic approaches.

\section{Acknowledgments}

We are thankful to Dr. J.-M. Hu from the Institute of Ecology and Evolutionary Biology at National Taiwan University for his kind assistance in the phylogenetic analysis. We are also grateful to R.-G. Chen, Y.-H. Chen, S.-C. Chuang, Y.-H. Lin, C.-C. $\mathrm{Wu}, \mathrm{J} .-\mathrm{H}$. Wu, and S.-P. Wu, who assisted us in the collection of earthworm samples. Special thanks are given to Mr. Y.-H. Lin for helpful comments and for providing information about the geological history of the Taipei area. This study was supported by the National Science Council of the R.O.C. (NSC92-2621-B-002-019) to J.-H. Chen.

\section{References}

Apakupakul, K., Siddall, M.E., Burreson, E.M., 1999. Higher level relationships of leeches (Annelida: Clitellata: Euhirudinea) based on morphology and gene sequences. Mol. Phylogenet. Evol. 12, 350-359.

Avise, J.C., 2000. Phylogeography: The History and Formation of Species. Harvard University Press, Cambridge.

Beauchamp, K.A., Kathman, R.D., McDowell, T.S., Hedrick, R.P., 2001. Molecular phylogeny of tubificid oligochaetes with special emphasis on Tubifex tubifex (Tubificidae). Mol. Phylogenet. Evol. 19, 216-224.

Bely, A.E., Wray, G.A., 2004. Molecular phylogeny of naidid worms (Annelida: Clitellata) based on cytochrome oxidase I. Mol. Phylogenet. Evol. 30, 50-63.

Borda, E., Siddall, M.E., 2004. Arhynchobdellida (Annelida: Oligochaeta: Hirudinida): phylogenetic relationships and evolution. Mol. Phylogenet. Evol. 30, 213-225.

Chang, C.-H., Chen, J.-H., 2005. Three new species of octothecate pheretimoid earthworms from Taiwan, with discussion on the biogeography of related species. J. Nat. Hist. 39, 1469-1482.

Chen, I.-H., Chang, C.-H., Chen, J.-H., 2003. The species composition and distribution of earthworms in Ilan. Chin. Biosci. 46, 56-65 (in Chinese).

Chen, J.-H., Shih, H.-T., 1996. A preliminary study of earthworms in Fushan Botanical Garden. Chin. Biosci. 39, 52-59 (in Chinese).

Chuang, S.-C., Wu, J.-C., Chang, C.-H., Chang, C.-H., Yang, K.-W., Lai, W.-S., Wu, Y.-W., Chen, J.H., 2002. The species composition and distribution of earthworms in northern Taiwan. Chin. Biosci. 45, 66-75 (in Chinese).

Easton, E.G., 1979. A revision of the "acaecate" earthworms of the Pheretima group (Megascolecidae: Oligochaeta): Archipheretima, Metapheretima, Planapheretima, Pleionogaster, and Polypheretima. Bull. Br. Mus. Nat. Hist. (Zool.) 35, 1-126.

Easton, E.G., 1982. Australian pheretimoid earthworms (Megascolecidae: Oligochaeta): a synopsis with the description of a new genus and five new species. Aust. J. Zool. 30, 711-735.

Erseus, C., Prestegaard, T., Kallersjo, M., 2000. Phylogenetic analysis of Tubificidae (Annelida, Clitellata) based on $18 \mathrm{~S}$ rDNA sequences. Mol. Phylogenet. Evol. 15 (3), 381-389.

Erseus, C., Kallersjo, M., Ekman, M., Hovmoller, R., 2002. $18 \mathrm{~S}$ rDNA phylogeny of the Tubificidae (Clitellata) and its constituent taxa: dismissal of the Naididae. Mol. Phylogenet. Evol. 22, 414-422.

Folmer, O., Back, M., Hoeh, W., Lutz, R., Vrijenhoek, R., 1994. DNA primers for amplification of mitochondrial cytochrome $c$ oxidase subunit I from diverse metazoan invertebrates. Mol. Mar. Biol. Biotechnol. 3, 294-299.

Heethoff, M., Etzold, K., Scheu, S., 2004. Mitochondrial COIl sequences indicate that the parthenogenetic earthworm Octolasion tyrtaeum (Savigny, 1826) 
constitutes of two lineages differing in body size and genotype. Pedobiologia 48, 9-13.

Hsu, S.K., Sibuet, J.C., 1995. Is Taiwan the result of arc-continent or arc-arc collision? Earth Planet. Sci. Lett. 136, 315-324.

Jamieson, B.G.M., Tillier, S., Tillier, A., Justine, J.L., Ling, E., James, S., McDonald, K., Hugall, A.F., 2002. Phylogeny of the Megascolecidae and Crassiclitellata (Annelida, Oligochaeta): combined versus partitioned analysis using nuclear (28S) and mitochondrial (12S, 16S) rDNA. Zoosystema 24, 707-734.

Kimura, M., 1980. A simple method for estimating evolutionary rates of base substitutions through comparative studies of nucleotide sequence. J. Mol. Evol. 16, 111-120.

Kumar, S., Tamura, K., Jakobsen, I.B., Nei, M., 2001. MEGA2: Molecular Evolutionary Genetics Analysis software. Bioinformatics 17, 1244-1245.

Michaelsen, W., 1922. Oligochaeten aus dem Rikks Museum van Natuurlijke Historie zu liden. Capita Zool. 1, 1-72 (in German).

Nylander, J.A.A., Erseus, C., Kallersjo, M., 1999. A test of monophyly of the gutless Phallodrilinae (Oligochaeta, Tubificidae) and the use of a 573-bp region of the mitochondrial cytochrome oxidase I gene in analysis of annelid phylogeny. Zool. Scr. 28, 305-313.

Palumbi, S., Martin, R.A., Romano, S., McMillan, W.O., Stice, L., Grabowski, G., 1991. The Simple Fool's Guide to PCR, Vers. 2. University of Hawaii Zoology Department, Honolulu, HI.

Pop, A.A., Wink, M., Pop, V.V., 2003. Use of 18S, 16S rDNA and cytochrome $c$ oxidase sequences in earthworm taxonomy (Oligochaeta, Lumbricidae). Pedobiologia 47, 428-433.

Shih, H.T., Chang, H.W., Chen, J.H., 1999. A review of the earthworms (Annelida: Oligochaeta) from Taiwan. Zool. Stud. 38 (4), 435-442.

Siddall, M.E., Burreson, E.M., 1998. Phylogeny of leeches (Hirudinea) based on mitochondrial cytochrome $c$ oxidase subunit I. Mol. Phylogenet. Evol. 9 (1) 156-162.

Siddall, M.E., Borda, E., 2003. Phylogeny and revision of the leech genus Helobdella (Glossiphoniidae) based on mitochondrial gene sequences and morphological data and a special consideration of the triserialis complex. Zool. Scr. 32, 23-33.

Sims, R.W., Easton, E.G., 1972. A numerical revision of the earthworm genus Pheretima auct. (Megascolecidae: Oligochaeta) with the recognition of new genera and an appendix on the earthworms collected by the Royal Society North Borneo Expedition. Biol. J. Linn. Soc. 4, 169-268.

Swofford, D.L., 2000. PAUP 4.0: Phylogenetic Analysis Using Parsimony (and Other Methods). Sinauer, Sunderland.

Teng, L.-S., 1996. Extensional collapse of the northern Taiwan mountain belt. Geology 24, 949-952.

Teng, L.-S., Lee, C.-T., Peng, C.-H., Chu, J.-J., Chen, W.-F., 2001. Origin and geological evolution of the Taipei Basin, northern Taiwan. West. Pac. Earth Sci. 1, 115-142.

Thompson, J.D., Higgins, D.G., Gibson, P.J., 1994. CLUSTAL W: improving the sensitivity of progressive multiple sequence alignment through sequencing weighting, position-specific gap penalties and weight matrix choice. Nucleic Acid Res 22, 4673-4680.

Tsai, C.-F., 1964. On some earthworms belonging to the genus Pheretima Kinberg collected from Taipei area in north Taiwan. Q. J. Taiwan Mus. 17, 1-35.

Tsai, C.-F., Shen, H.-P., Tsai, S.-C., 2000a. Native and exotic species of terrestrial earthworm (Oligochaeta) in Taiwan with reference to Northeast Asia. Zool. Stud. 39, 285-294.

Tsai, C.-F., Tsai, S.-C., Liaw, G.-J., 2000b. Two new species of pontandric pheretimoid earthworms belonging to the genus Metaphire (Megascolecidae: Oligochaeta) from Taiwan. J. Nat. Hist. 34, 1731-1741. 